\section{EL EROTISMO FEMENINO Y LA CONSTRUCCIÓN SIMBÓLICA DEL CUERPO EN SABOR A MÍ DE CECIILIA VICUÑA}

FEMALE EROTISM AND SYMBOLIC CONTRUCCTION OF THE BODY IN SABOR A MÍ BY CECILIA VICUÑA

\section{Abstract:}

Con la propuesta poética de Cecilia Vicuña With Cecilia Vicuña's poetic proposal contenida en su libro Sabor a mí encontramos contained in his book Sabor a mí we find the la transgresión a un sistema que, a través, transgression to a system through which are de diversas estrategias no ha hecho más found various strategies that have only just que administrar nuestros cuerpos a su manage our bodies as required and have been conveniencia y hemos permanecido ocultando hiding what is inherent in our nature: desires. lo que es inherente a nuestra naturaleza: los The author invites us to detach ourselves deseos. La autora nos invita a desligarnos de from the censorship we live in speaking from la censura en que vivimos hablando desde su his female corporeality. corporalidad femenina.

Palabras claves:

Cuerpo, erotismo, sexualidad, poesía.

\section{KEY WORD:}

Body, sexuality, eroticism, poetry.
"Estoy obligada a ser un ángel con la pelvis en llamas"

(Sabor a mí, 2007.)

El presente artículo abordará la escritura poética de Cecilia Vicuña, poeta, artista y cineasta nacional, que emerge en la escena nacional en los 60, pero que desarrolla su actividad artística primordialmente en el extranjero. Es autora de más de una decena de libros de poesía. Algunos de ellos tienen formato bilingüe, como es el caso del libro que se utilizará como corpus Sabor a mí (2007).

Este libro ${ }^{1}$ está constituido por dos tópicos fundamentales: el político y el del erotismo corporal ${ }^{2}$. Respondiendo con los intereses de quien habla se orientará el análisis hacia éste segundo, puesto que transgrede casi violentamente a las estructuras sociales represivas hacia las mujeres, motivo por el cual su libro nunca fue publicado en Chile, justamente por este tenor inadecuado y rupturista. ${ }^{3}$

A pesar de ser éste su primer libro (1971) es uno de los últimos en aparecer en Chile (2007), luego de ser rechazada su publicación lo re-escribió en Inglaterra en donde vivió el impacto por el golpe militar sufrido en el país (1973). Es por esto que el libro resurge por la contingencia del presente y está constituido por pinturas, textos, recortes, desechos y poemas que son los que otorgan a la obra la intimidad sexual a la que antes se hacía referencia.

El aspecto político del libro es absolutamente atingente a la época como así también cuando se habla de género, puesto que los alcances de la sexualidad están presentes a cualquier escala social y más aún en los discursos amparados por el poder. Pero el interés de esta investigación, quizás arbitrario, apunta a que originalmente el texto estaba constituido, aunque, también con una mirada política, sin la contingencia del golpe de estado, por lo tanto, en esencia el motivo que mantuvo a este libro fuera del campo literario nacional fue su carácter erótico, desde la perspectiva de quien escribe y sin el afán de ignorar su constitución ni propuesta se considerará que la verdadera revolución está en los poemas, cuyo discurso produce un efecto catártico en relación a la siempre reprimida escritura de mujeres.

1 Publicado el 2007 por las Ediciones Universidad Diego Portales, pero que cuya primera publicación data del año 1973 con doscientos cincuenta ejemplares hechos a mano en Inglaterra (donde la autora se encontraba estudiando arte) cada ejemplar fue diferente y estaban compuestos por páginas teñidas a mano, papel volatín, papel dorado, etc. El sabor a mí de ese año medía 16×20 centímetros y era una obra de arte en sí mismo, también una especie de antología de sus primeros trabajos.

2 Estos poemas surgen de los diarios que escribía en esa época (1971) y constituyen el primer proyecto de Sabor a mí cuyo título proviene de un bolero.

$3 \mathrm{Si}$ bien la primera publicación fue en Inglaterra, como se explica anteriormente, los poemas de Sabor a mí o Sabor a mí fueron escritos entre 19661971 en Chile, constituyéndose por cien poemas y teniendo contrato de publicación con Ediciones Universitarias de la Universidad Católica de Valparaíso para este último año, pero eso nunca ocurrió. 
Haciendo alusión a la crítica que se ha encargado de calificar a la escritura de mujeres desarrollada en el país, como así también fuera de él, siempre remitiéndola al silenciamiento de la vida privada, a través, de diarios íntimos primeramente y luego apropiándose de formas más legitimas del canon literario como la poesía o la novela. Estos textos definen la diferencia sexual y dan cuenta de cambios culturales e históricos. La mujer tiene mucho que decir también y aportar sobre la construcción de género, en donde se ha conformado una subjetividad desconocida que surge a partir de una realidad histórica de subordinación. Hablar como mujer o como hombre es también hablar desde una construcción cultural que oprime a uno u otro en paradigmas morales, sociales, políticos, etc.

Con respecto a lo anterior Judith Butler" se hace cargo de lo que ella llama "vida corporal", parafraseando lo que ella sostiene, expone que la diferencia sexual viene dada por las diferencias materiales, pero que también están marcadas por las prácticas discursivas, el sexo no sería solo una norma sino que además una práctica reguladora para diferenciar los cuerpos que controla, a través, de la reiteración de normas. Dentro de esto cabe el concepto de "performatividad", práctica reiterativa mediante la cual el discurso produce los efectos que nombra. Por tanto, con la materialidad del cuerpo y las normas reguladoras del sexo se consolida el imperativo heterosexual. El sexo no sería más que una norma cultural que gobierna la materialización de los cuerpos. (Butler, 2002: 18-19)

En definitiva, podemos cuestionar las perspectivas de análisis con respecto a la corporalidad, al sexo y a la construcción de género, pero si lográramos aunar criterios, sin duda sería que todos estos conceptos están regulados por discursos, que han llegado a imperar y regular además de nuestros cuerpos, nuestra propia conciencia.

La poesía de Cecilia Vicuna representa la represión en la que ha vivido la mujer históricamente como así también incita a una revolución de los deseos, en donde el placer y la exhibición del cuerpo nos libera de una construcción simbólica y cultural de éste.

Primeramente, consideraremos al cuerpo, además de una entidad física es también una construcción simbólica. Por tanto sujeto a estructuras culturales. Es a partir de estas estructuras desde donde proviene la norma y los sistemas de valores que rigen el comportamiento de los hombres. Este sistema de valores es el que ha sido mayoritariamente represivo para la mujer y por tanto subyugada al poder, aspecto que ha sido desde siempre administrado por los hombres.

4 Es una filosofa post-estructuralista, profesora en la universidad de California, ha realizado importantes aportes en los campos del feminismo, la teoria Queer, la filosofía política y la ética. Lo mencionado en el trabajo corresponde a ideas expuestas en su libro Cuerpos que importan: sobre los límites materiales y discursivos del sexo. (1993)
Si nos adentramos en el ámbito privado de la sexualidad, es paradójicamente de público conocimiento que el rol activo lo tienen los hombres, por tanto la mujer participa pasiva y funcionalmente de la sexualidad, determinando la sexualidad de la mujer con el rol de la maternidad e invisibilizando sus deseos e instintos que se validan como propios del hombre (sexo masculino).

La actividad sexual de la mujer se restringe por una pasividad que funda el resguardo de una feminidad que no es otra cosa que la camisa de fuerza para la represión de la sexualidad de la mujer. Según Freud, a partir de sus teorías psicoanalistas, considera que lo masculino constituye al sujeto, por tanto la actividad y la posesión del pene, (el gran órgano sexual que rige estas teorías y funda la cultura falocéntrica ${ }^{5}$ ) y lo femenino perpetuará el objeto, la pasividad y... el órgano genital castrado.

Desde esta perspectiva, el psicoanálisis ha servido para determinar la sexualidad de la mujer y por tanto supeditada, también, en sus roles sociales, económicos, culturales, etc. Sobre esto se han formulado diversas críticas, entre ellas Luce Irigaray, quien ha criticado a Freud porque la sexualidad no ha sido definida en relación con otro sexo que el masculino.

Para Freud no hay dos sexos cuyas diferencias se articularían en el acto sexual y, en un plano más general, en los procesos imaginarios y simbólicos que regulan un funcionamiento social y cultural. Lo "femenino" es siempre descrito como defecto atrofia, reverso del único sexo que monopoliza el valor: el sexo masculino. Y así sucede con la celebérrima "envidia del pene". (Irigaray, 2009: 52)

El sexo por placer es un ámbito sancionado y restrictivo para las mujeres, más aún el erotismo. De este campo semántico se apropia Cecilia Vicuña en Sabor a mí, denunciando que la mujer está obligada a ser un ángel con la pelvis en llamas. Vicuña transgrede y escribe en absoluta libertad construyendo su discurso poético con el cuerpo de la mujer que yace oculto tras un velo moral, mítico y patriarcal que criminaliza sus deseos y la mantiene sujeta a dos dicotomías extremistas que han servido como representación de ésta: La mujer fatal y la de Ángel del hogar; Lectura absolutamente masculina de la construcción simbólica de la mujer.

La mujer fatal es un arquetipo que ha construido la literatura europea y que ha heredado la hispanoamericana para representar a la mujer seductora y hechicera que utiliza sus encantos para atraer al hombre y llevarlo a su destrucción (Mujer pecadoraportadora del mal) como por ejemplo, podemos personificar en la figura de Eva $Y$ Lilith, aplicada a la cosmovisión cristiana y el ángel del hogar a María, como la figura

5 El comentario es mío.

(a) Culturas y Literaturas, abril 2015 ISSN: $1885-3625$ 
obediente, sumisa, abnegada, recatada, como una forma de reivindicar la imagen de la mujer, poseyendo una moral superior, como ejemplo de virtud ${ }^{6}$.

Esta dicotomía planteada por los discursos fundacionales de carácter mítico, por tanto religioso y moral reproduce un modelo occidental de representación que ha reproducido nuestra cultura y que ha imperado en las diversas áreas del conocimiento.

A partir del siglo XIX, con el surgimiento de de las ciencias positivistas es la naturaleza del cuerpo de la mujer la que determina su rol social y cultural. Éste es el de resguardar el hogar y por tanto fortalecer la sociedad, a través, de la familia y la maternidad. Su rol es restringido a lo emotivo-educativo, es por esto que el abandono del hogar para el desarrollo intelectual y laboral es una importante crítica con la que debe cargar.

Sobre esto se ha referido, entre otros, Foucault en su Historia de la sexualidad, dejando al descubierto los mecanismos de poder que operan en los ámbitos jurídico y discursivo. Como él ha señalado la sexualidad tiene mayor instrumentalidad para el poder, entre uno de los conjuntos estratégicos que ayudan a desplegar estos propósitos está la llamada "Histerización del cuerpo de la mujer". (Foucault. 1977: 62)

El cuerpo de la mujer fue analizado- calificado y descalificado- como cuerpo integralmente saturado de sexualidad; según el cual ese cuerpo fue integrado- bajo el efecto de una patología que le sería intrínseca, al campo de las prácticas médicas; según el cual, por último, fue puesto en comunicación orgánica con el cuerpo social (cuya fecundidad regulada debe asegurar), el espacio familiar (del que debe ser un elemento sustancial y funcional) y la vida de los niños (que produce y debe garantizar, por una responsabilidad biológico-moral que dura todo el tiempo de la educación): la Madre, con su imagen negativa que es la "mujer nerviosa", constituye la forma más visible de esta histerización.

La importancia que tiene el cuerpo para el debate sobre el rol de la mujer y sus representaciones culturales es que éste ha servido para su propia subordinación. Puesto que la ciencia ha categorizado al cuerpo de la mujer a partir de sus procesos biológicos y sus probables desórdenes mentales, atribuyéndoles inestabilidad y fragilidad, situación que la han distanciado del poder y la han limitado a su rol reproductor.

Con respecto a esto dice Luce Irigaray ${ }^{\underline{Z}} \mathrm{Su}$ condición de subdesarrollo que produce de su sumisión por/a una cultura que las oprime, las utiliza, las "hace moneda", sin que ellas saquen mayor beneficio. Salvo en el casi monopolio del placer masoquista, del trabajo doméstico, y de la reproducción. ¿Poderes de esclava?

6 Sobre estas dicotomías simbólicas aborda Gilbert Durand en Las estructuras antropológicas de lo imaginario: Introducción a la arquetipología general.

7 Irigaray, Luce. Ese sexo que no es uno. España, Madrid: Ediciones Akal, 2009. Impreso.
Contra estos poderes de esclava levanta su poesía Cecilia Vicuña, desligándose de este cuerpo, que ha sido la casa para oprimir a la mujer y la ha negado de su sexualidad. El cuerpo para Vicuña es el medio para el goce de los placeres, por tanto la exhibición de éste en su poética es también el estandarte para una liberación sexual que se simboliza en un erotismo corporal.

Se produce una apertura a un nuevo erotismo, desplegado por distintas vías, donde ya no prima lo genital dictado por la matriz de sexo-género; un erotismo menos rígido, más móvil y más difuminado. De este modo, un erotismo rizomático, desplaza la dualidad -que obliga una mutua exclusión de las partes para poder sobrevivirpermitiendo la entrada a múltiples posibilidades, que se suman unas a otras, abriendo puertas a un erotismo no disciplinario.

Para acotar el análisis textual a las categorías presentadas hasta ahora escogeré algunos poemas contenidos en el libro antes mencionado ${ }^{9}$ y que nos servirá como corpus principal de análisis.

El poema "Madre e Hija", de alguna manera sintetiza el rol biológico y cultural de la maternidad, pero la madre que es representada en este poema es una que se "prostituye con facilidad". Una madre amistosa que utiliza su cuerpo como moneda de cambio para beneficios económicos, es decir, su cuerpo es una mercancía. Es descrita de esta manera: "Tiene las nalgas hundidas y su máximal aspiración es negar la existencial de toda la humedad, de lo entreabierto que hay/ quitar esos mundos de la tierra, para quel sus hijas sean planas muñecas."

Esta mujer que se prostituye con facilidad quiere negar sus deseos naturales, el de excitarse, por ejemplo, oculta el mundo de los deseos para reproducir en su hija un modelo que disimula y niega hasta sus propios órganos genitales "De toda la humedad de los entreabierto que hay", la vagina es innombrable siquiera en esta preservación del modelo a través de la enseñanza de la madre a la hija.

La noche en el poema es el escenario para desatar los deseos más perversos a través de los "fantasmas de piel", el extravío de la madre (locura-enajenación) provoca la profanación del cuerpo de sus hijas "las viola sucesivamente". Si pretendemos analizar estos versos desde una perspectiva simbólica podemos asociarlo con las estructuras que Durand desarrolla en dos regímenes: el diurno y el nocturno.

8 La cita corresponde a parte de las reflexiones finales que expone Catalina Balbontín en el artículo "Mujeres, imaginario corporal y prácticas sexuales. Vivencias de la corporalidad y el erotismo". Investigación para optar al grado de magíster en Estudios de género y cultura, Mn. Ciencias sociales, Universidad de Chile, 2008

9 El libro Sabor a mí publicado por la Editorial Diego Portales, pero además se consideran poemas contenidos en una antología publicado por la editorial LOM el 2010 y que incluye otros poemas que están exentos en el primero

Revista Internacional de Culturas y Literaturas, abril 2015 
Estos versos se conectan con este último, ya que, en éste se sitúa lo místico, la inversión, la intimidad; el esquema verbal oscila entre los conceptos de: Descender, poseer y penetrar. Además de lo anterior entre los "arquetipos sustantivos" del régimen nocturno encontramos, entre otros, al Niño, la Noche, la Madre, el Hogar, la Mujer, el Alimento, la Sustancia, etc. Campo semántico que en este poema despliega sus significaciones. Lo nocturno es un descenso entre los límites de ángel y animal.

Las hijas no conocen otra forma de contacto sexual, por lo que tienen un "aire de dominar el mundo con simulada timidez". Es decir, el contacto incestuoso con la madre y con el órgano genital feminal, pero más aún con la exploración de los placeres prohibidos las deja en un estado de superioridad por sobre el simulacro de la timidez y la negación de los deseos que deben representar.

El poema "Mastaba", juega con la ilusión de la palabra Masturbación, tema que es transversal en varios poemas contenidos en el libro, es un poema breve que con alusiones directas a los órganos sexuales y a la corporalidad exhibe los fluidos genitales como parte de la consumación de este acto erótico y de auto-placer que es la masturbación.

El contacto físico y las tocaciones son el preámbulo que hacen volar al hablante lírico, lo expresa del siguiente modo: "Tu mano en mi sexo/ mi impulsaba/ como pájaro húmedo/ Floté gozosamente en la ocasión/me mojé hasta las rodillas". Con un lenguaje más bien coloquial la poeta alude claramente a la máxima excitación que le provoca la masturbación provocada por otro.

La masturbación hacia otro es parte de un intercambio sexual en donde prima el juego erótico y la satisfacción de los deseos. Sin embargo, siempre ha sido un tabú y para ello se han empleado diversos mecanismos de manipulación y sanción, como por ejemplo es tratado en la llamada "Pedagogización del sexo del niño" aspecto que desarrolla Foucault $\frac{10}{}$, como se ha mencionado anteriormente. De esta manera el discurso ampara el control de los instintos, es decir lo natural y sanciona la libertad de estos, la preocupación por "el niño masturbador" se extiende en todo el siglo XIX y sus alcances son inconmensurables a la hora de abordar el control de la sexualidad.

En Sexo solitario. Una historia cultural de la masturbación (2007), Laqueur explica que: “La historia de la masturbación es la historia de la imaginación, la soledad y el secreto, lo público y lo privado, el exceso, la adicción y el control en las diferentes etapas de nuestro desarrollo de una ética sexual individual.." (331). Mastaba, no es un poema que alude al placer solitario en sí, puesto que el acto es realizado por otro, sino al erotismo, al exceso, a la adicción por los deseos. Es el goce sexual lo que se pretende, la búsqueda

10 En su libro Historia de la sexualidad, específicamente en el Capítulo IV llamado "El dispositivo de la Sexualidad", plantea cuatro categorías que develan los mecanismos del poder que han modelado al sexo, una de ellas es el Dominio (Aspecto 3 tratado en el texto) que tiene relación con la instrumentalidad que tiene la sexualidad para el poder, por lo que se ha buscado de diferentes formas reducir el sexo solo a su función reproductora. del placer, que ha sido satirizado por la tradición moral y cristiana que nos rige y nos culpabiliza por sentir lo que es inherente a nuestra naturaleza.

Nuestra cultura está fundada en el castigo, el sacrificio y la constante culpa infringida a base del temor por no alcanzar la añorada redención. Nuestra cultura es la del pecado, es la del arrepentimiento, fomentando una hipocresía constante, que nos purifica si nos acercamos al dolor y nos categoriza de enfermos si buscamos el placer. El mismo sistema económico que nos rige nos enseña a desear lo que no tenemos y nos ofrece los mecanismos para adquirirlo. "La angustia por la masturbación era una expresión de la angustia por un nuevo orden político económico escrito en el cuerpo" (Laqueur. 2007: 334).

La poesía de Cecilia Vicuña no queda exenta de la ironía, por ejemplo, en el poema llamado "Poema Puritano", cuyo título es absolutamente opuesto a lo contenido en él, ya que alude directamente a los genitales, a la penetración y a la masturbación, aspectos que nos permitirán abordar sobre lo postulado por el Psicoanálisis en relación a la "envidia del pene".

El poema nos dice: "Me encanta mi sexo/ Entre tu sexo y el mío/ no sé cuál elegir", versos que nos permiten dar cuenta de que a pesar de que el sujeto lírico expresa estar encantada y muy agradada con su sexo, titubea ante la idea de poseer un pene y controlar su sexo. Además de lo anterior el poema no trasgrede la heteronormatividad puesto que se expone la complementariedad de los órganos sexuales, pero sin afán reproductivo, el modelo binario de la sexualidad se representa en este poema "puritano" y quizás por lo mismo el nombre.

La unión entre macho y hembra, es de los que nos habla este poema. "El sistema "heteronormativo" se torna perverso porque posee el control sobre la estética de los cuerpos de los ciudadanos vigilándolos - por tanto normándolos-y excluyendo a aquellos que salen del molde" (Arteaga, 2009:91). La hablante se mofa de esta normatividad de los órganos sexuales, calificando al masculino como "divertido" y al de ella (el femenino) como de "tan bonito". Por tanto, la poeta juega con la tradición sobre la primacía del órgano masculino, en relación al femenino que ha sido invisibilizado y subvalorado al punto de otorgarle importancia solo como morada del pene ${ }^{11}$.

La poeta continúa diciendo: "Pero lo que hay/ que subrayar/ es cómo cabe el tuyo/ dentro del mío/ siendo tan grande/ y de color brillante". De esta manera la magnopresencia del órgano masculino se acentúa mucho más, exacerbando sus cualidades viriles y aludiendo al coito como a un acto inexplicable, en donde el pene es lo opuesto, pero a la vez lo complementario del sexo femenino (heteronormatividad). La poeta

11 Aspecto desarrollado por Freud en su texto "La Feminité" y aludido por Luce Irigaray. Cit. 
finaliza con un verso que más bien parece consigna: "Morir con la mano en el sexo". Aludiendo a la importancia de la masturbación para la apropiación de los deseos.

Uno de los poemas más extensos incorporados es el llamado "Amada Amiga" y refleja la ilusión lésbica entre esta amiga y la hablante lírico. Los deseos de esta mujer hablante aspiran a concretarse en sueños y es a través de signos tan potentes como la falda o un calzón como representa este anhelo de posesión.

Es, a través, de la descripción como la hablante va poseyendo a su amiga, puesto que el detalle de los gestos y la mirada minuciosa hacia su corporalidad se transforman para la hablante en el campo minado de sus deseos paulatinos y torpes. Su amiga es su objeto de deseo, es comparable para ella a un "país con ciudades" de Lorenzetti (pintor italiano del siglo XX) ella es el lugar al que se ansía regresar, ella constituye todo lo que se ve.

Le habla a esta amiga: "No sufras porque en este cuadro/ dos mujeres se acarician/ yo alguna vez te acariciaré". Esta amiga es alguien que está dominada por las convenciones sociales y que mira la homosexualidad como un pecado y una perversión digna de ocultar. El amor de quien habla la lleva a desear "ser hombre" para seducirla y obligarla a que abandone su casa. Luego la hablante lirico se retracta de esta idea, puesto que el hombre tienen una insatisfacción sexual permanente por sus deseos incesantes de penetración.

La hablante quiere un distanciamiento con la metrópolis, para abandonar sus deseos por la tranquilidad que implicaría liberarse de ellos. Su amiga le produce temor porque no puede amar como ella, ni sentir, ni experimentar lo que en ella se desborda: su lado bestial. El lado humano, es decir la racionalidad controla estos deseos e impulsos que opuestos y dicotómicos con la animalidad priman y dominan su actuar.

Finaliza el poema otorgando un retrato físico, en donde su corporalidad es a la vez distancia y cercanía con lo deseado: "Qué daría la muerte/ porque no tuvieras/ esos ojos redondos/ ni esos senos/ ni esos muslos/ para dominarte/ envolverte y guardarte/ de una vez por todas". El poema deja una sensación de revancha entre el hablante y su objeto de deseo: su amiga. Es la ilusión erótica de quien ama en la prohibición, por tanto es en la imaginación en donde puede desatar sus deseos sin restricción, lo imaginario es el espacio de libertad en donde transitan los instintos más bestiales.

El poema "El centro de la Mandala" expresa la banalidad que puede significar una relación sexual frente a satisfacciones incorpóreas, como lo puede ser el contacto directo de la mirada, en donde no hay roce corporal, pero que puede significar una cercanía mayor que el acto mismo de tocarse. El sujeto poético no solo alude al contacto físico, como en los poemas anteriores, validando que la verdadera perfección es encontrarse, fluir con otro y satisfacer los sentimientos, aspecto que el "coito" no pude suplir. En sus palabras: “Un beso es poco para míl Un coito es demasiado poco/ Un coito no sabe contener ni expresar/ ni satisfacer mi sentimiento de ti".

De este modo la autora, también nos dice que debemos hablar de nuestros instintos, deseos, de nuestra relación animal, pero que no es suficiente la satisfacción de los deseos carnales para el hombre, puesto que también somos interior, y los afectos navegan en un barco diferente del de nuestro deseos que buscan satisfacerse legítimamente, pero que no se trata solo de eso nuestra naturaleza.

Por último, mencionaré al poema "Nuevos diseños eróticos para muebles" que es más bien un sarcasmo sobre las posiciones corporales. El poema está acompañado por el dibujo de una mujer que sentada de rodillas sobre un mueble que tiene forma de peldaño, es decir, su tronco se recuesta en la altura y la pelvis queda en libertad de movimiento exhibiendo las nalgas con el título de "mesa de trabajo". De este manera invita a quienes optan por la rigidez a innovar: "Soñando con un mundo vasto/ hemos llegado a la certera conclusión/ de que las posiciones del cuerpo/ en el mundo civilizado/ son demasiado limitadas".

Por tanto, podemos vislumbrar que ese "mundo civilizado" al que alude anteriormente ha regulado hasta la forma en que nos sentamos, en que nos movemos y manejamos nuestros cuerpos como medio por el cual interactuamos con el mundo. Nos invita a movernos y a apropiarnos de nuestro cuerpo con libertad, desligándose de las limitaciones culturales con las que debemos cargar.

La poesía de Cecilia Vicuña hace un levantamiento de los deseos de la mujer, por extensión de la mujer como ente social, histórico, artístico y literario, a través de la corporalidad. Reivindica la bestialidad del humano y lo pone como centralidad y en oposición con lo humano/ raciocinio, puesto que ambos no están en la misma altura, lo natural es la verdad de lo que somos realmente, somos también nuestros deseos. Sin obviar que éste no solo se fundamente en las relaciones heterosexuales sino también homosexuales. EL lesbianismo es también un medio para liberar a la mujer de sus ataduras sexuales.

El cuerpo en la poesía de Cecilia Vicuña es el arma con que dispara contra este mundo rígido y convencional, es la hoja en blanco en la que debemos escribir nuestra propia historia y no esperar a que nos la cuenten. La mujer debe abandonar el temor discursivo de llamar las cosas por su nombre, puesto que la poesía es también un arma social que nos permitirá actuar y hablar con libertad.

Es hora de que el cuerpo femenino se desligue de la "patologización" a la que ha sido sometido y lo ha mantenido en una inferioridad sexual o como un "continente negro" según Freud, la exclusión en que se ha visto sometida la mujer no hace más 
que devolvernos un imaginario femenino fragmentado, en donde lo femenino es en función del sujeto masculino, la mujer a propósito de lo fálico.

El placer es la búsqueda legítima de la mujer, el sacrificio de sus deseos debe sumergirse tras este universo en expansión que es el imaginario femenino, debe despojarse de la maraña construida por un sistema opresor que no hace más que moldearnos a su antojo y construir arquetipos asexuados y anormales que ocultan su propia naturaleza.

\section{REFERENCIAS BIBLIOGRÁFICAS}

Arteaga, J. C. “La heteronormatividad y la nada”, Ecuador debate 78 (2009), pp. 89-98.

Bataille, G. El erotismo. Internet. Pdf.

Butler, Judith. Cuerpos que importan. Sobre los límites materiales y discursivos del "sexo". Buenos Aires, Argentina, Paidos. 2002. Digital.

Castro Merrifield, F. "Gilbert Durand y el método arquetipológico", Acta Sociológica, núm. 57, enero-abril 2012, pp. $51-64$.

Foucault, M. Historia de la sexualidad 1. La voluntad de saber. Traductor Ulises Guiñazú Internet. http://www.pueg.unam.mx/images/seminarios2015_1/identidad/u_4/fou_mic.pdf

Irigaray, L. Ese sexo que no es uno. España, Madrid: Ediciones Akal, 2009. Impreso.

Laqueur, T. Sexo solitario. Una historia cultural de la masturbación. Buenos Aires, Argentina: Fondo de cultura económica de Argentina, S.A. 2007. Impreso.

Le Breton, D. Antropología del cuerpo y modernidad. Buenos aires: Nueva visión, 2002.

Potok, M. El texto femenino: El discurso literario como expresión de la diferencia. 2009. Revista Itinerarios. Vol. 10

Vicuña, C. Sabor a mí. Santiago, Chile: Ediciones Diego Portales, 2007.

----, Soy Yos Antología, 1966-2006. Santiago Chile: LOM Ediciones. 2010. 